\title{
Prevalence of photoprotection and its associated factors in risk group for skin cancer in Teresina, Piauí
}

\author{
Fernanda Ayres de Morais e Silva Cardoso ${ }^{1}$ \\ Viriato Campelo ${ }^{2,3}$ \\ Camila Aparecida Pinheiro Landim Almeida ${ }^{1}$ \\ Amanda Eugênia Almeida Rocha ${ }^{4}$
}

\author{
Gerardo Vasconcelos Mesquita ${ }^{1,2}$ \\ Maria do Carmo de Carvalho e Martins ${ }^{1,2}$ \\ Regina Silva Rabelo ${ }^{2}$ \\ Jadson Lener Oliveira dos Santos ${ }^{5}$
}

DOI: http:/ /dx.doi.org/10.1590/abd1806-4841.20174831

\begin{abstract}
BACKGROUND: The incidence of skin cancer has increased worldwide, particularly melanoma rates, which had a mean development of $2.6 \%$ a year in the last 10 years. The agreement on the relation between long-term or chronic exposure to the sun and the emergence of these neoplasias has made several workers who perform activities exposed to solar radiation to form a risk group for the development of skin cancer, community health agents included.

OвJестіVEs: To analyze the prevalence of sunscreen-use-related factors to skin cancer in a labor risk group.

Methodology: Cross-sectional study with community health agents selected through simple random sampling. After collecting data using semi-structured interviews, a descriptive analysis was performed for the qualitative variables, bivariate analysis was employed for checking the association between sunscreen use and sociodemographic, occupational and knowledge about skin variables, and multivariate analysis was conducted to check independent variables associated to sunscreen use. A $5 \%$ significance level was used.

RESUlTs: Of 261 health gents selected, 243 were able to participate in the study. The prevalence rate of sunscreen use was $34.2 \%$ (95\% CI: 28.2-40.2). Factors associated with sunscreen use were female sex, advanced age, use of sunscreen in situations when the skin got burnt, knowledge of the negative effects of the sun on the skin and skin cancer history.

Conclusions: The prevalence found reveals that there is a need for implementing educational strategies in health services regarding photoprotection.
\end{abstract}

Keywords: Primary prevention; Skin neoplasms; Sunscreening agents

\section{INTRODUCTION}

Skin cancer is a major public health problem whose incidence has been increasing dramatically worldwide over the past decades, particularly melanoma rates, which had a mean increase of $2.6 \%$ per year over the past 10 years. This increased incidence occurs even with the efforts of public actions and policies to enhance the adoption of safety measures regarding sun exposure. ${ }^{1,2}$

Estimates from the National Cancer Institute (INCA) show, for the year 2014, 98,420 new cases of non-melanoma skin cancer in men and 83,710 in women in Brazil, which correspond to an estimated risk of 100,75 new cases per 100,000 men and 82.24 new cases per 100,000 women. For melanoma skin cancer, the incidence is smaller (2,960 new cases in men and 2,930 in women), but its lethality is high. ${ }^{3}$

Chronic and excessive exposure to ultraviolet radiation is strongly associated with different pathological changes in skin, including skin cancer. Thus, protective measures and use of sunscreens are of particular importance in the prevention of skin cancer.
The development of new products and the improvement of technical conditions for the production of sunscreens have permitted the emergence of broad spectrum sunscreens and the increase of the efficiency and effectiveness of protection against ultraviolet radiation and hence against skin cancer. ${ }^{4}$

Whereas awareness of the health severity of skin cancer is small among health professionals and individuals in general and that the use of sun protection is crucial for the reduction of skin cancer, initiatives for the expansion of knowledge and change of habits by the exposed population are necessary.

The actions developed by the National Program to Fight Skin Cancer, organized by the Brazilian Society of Dermatology in the last 14 years, have shown that much of the population is exposed to the sun without protection. In the year 2013, more than 28 thousand people were assisted throughout Brazil, and about $12.74 \%$ of them were diagnosed with skin cancer. Moreover, $67.57 \%$

\footnotetext{
Received on 11.06.2015

Approved by the Advisory Board and accepted for publication on 11.11.2015

Study conducted in Teresina (PI), Brazil.

Financial support: none.

Conflict of interest: none.

Centro Universitário Uninovafapi - Teresina (PI), Brazil.

Universidade Federal do Piauí (Ufpi) - Teresina (PI), Brazil.

Universidade Estadual de Campinas (Unicamp) - Campinas (SP), Brazil.

Universidade de Pernambuco (UPE) - Petrolina (PE), Brazil.

Faculdade Facid-DeVry - Teresina (PI), Brazil.

C2017 by Anais Brasileiros de Dermatologia
} 
revealed that they used to be exposed to the sun with no protection. Regarding gender, in $2013,73.15 \%$ of men and $54.16 \%$ of women revealed that were exposed to the sun without any protection. ${ }^{5}$

In Piauí, a tropical state with high UV index, the analysis of data obtained in the 2009 and 2010 campaigns found that, of 1,141 assisted individuals, $73.1 \%$ were exposed to the sun without any protection and $10.7 \%$ had cancer skin. Personal and family history of epithelial neoplasia, skin color other than black, and male sex were associated with higher chances of developing skin cancer. ${ }^{6}$

The consensus on the relation between prolonged and chronic sun exposure and emergence of skin cancer causes more workers who carry out their activities exposed to solar radiation - including community health agents - form a risk group for development of skin cancer. ${ }^{7}$

Several studies of ultraviolet radiation dosimetry demonstrated that occupational exposure to solar radiation exceeds the limits deemed safe by the International Commission on Non-Ionizing Radiation Protection (ICNIRP) in several exposed workers, such as building contractors and farmers. Meta-analyzes recently published provide epidemiological evidence that outdoors workers undergo a significantly increased risk of developing non-melanocytic skin tumors compared with indoor workers. The association with increased risk of melanoma was less evident. ${ }^{8,9}$

According to the above considerations, the following question emerged: what is the prevalence and factors associated with the use of sunscreen in a group of workers at risk of developing skin cancer?

\section{METHODS}

We conducted a cross-sectional descriptive study of individuals of both genders registered as health agents in Fundação Municipal de Teresina, in Teresina, PI.

The study excluded workers who were on vacation or work leave, those who worked in office activities in the company and health agents with less than a year of intermittent work.

For sample size calculation purposes, it was taken as a reference parameter the minimum prevalence of sunscreen use of approximately $27 \%$, estimated by the results found in the latest National Campaign to Fight Skin Cancer held by the Brazilian Society of Dermatology. ${ }^{5}$

Considering also a margin of error of $5.5 \%$ and a confidence level of $95 \%$, the sample size was calculated according to the following formula: $\mathrm{n}_{0}=\underline{\mathrm{z}} \mathrm{pq}$

$\mathrm{d}^{2}$

Where $\mathrm{Z}$ is the normal curve for the established confidence level (in this case, $Z=1.96$ ); $p$ is the reference parameter (i.e., $p=0.27$ ); $q=1-p$ (therefore $1-0.27=0.73$ ); and $d$ is the margin of error (in this case, $d=0.055)$.

$$
\text { Using values, we found: } \mathrm{n}_{0}=\frac{1.96^{2} \times 0.27 \times 0.73}{0.055^{2}}=261
$$

The selection of community health agents was given by a simple random sampling without replacement. The 1,554 community health agents registered were listed and subsequently randomly chosen by BioEst 2.0 program.

After personal interview, which used structured questionnaire with objective questions, an analysis of the collected data was conducted.
Descriptive analysis of data was performed using mean and standard deviation (SD) of the quantitative variables and using ratios and $95 \%$ confidence interval of the qualitative variables.

In bivariate analysis to assess the association between the use of photoprotection and sociodemographic, occupational and knowledge on the skin variables, we used the Pearson's chi-square test $\left(\chi^{2}\right)$.

Variables relating to education, skin color and skin type were re-categorized for better analysis, as follows:

a) Education: up to high school and college or further;

b) Skin color: light, brown and dark/black;

c) Skin type: burns easily, burns moderately and burns a little, rarely or never.

A multivariate analysis was conducted with variables presenting $\mathrm{p}$ value $<0.05$ in the bivariate analysis, and Poisson regression was used to verify the independent variables associated with the use of sun protection, controlled for possible confounding factors - adjusted prevalence ratio (PR). Results were expressed by PR and 95\% confidence interval (95\% CI) using a model clustered in blocks, ordered according to the precedence in which they acted on the use of sun protection. ${ }^{10}$ Thus, the sociodemographic factors were considered distal determinants, which acted directly on other groups: occupational factors and factors related to knowledge on the skin.

Associations were evaluated using the Wald test.

All analyzes were performed with the aid of SPSS software (Statistical Package for Social Sciences) for Windows ${ }^{\circledR}$, version 18.0, considering the significance level of $5 \%$.

The research project was approved by the Ethics Review Board of Centro Universitário Uninovafapi, under CAAE 01587014.4.0000.5219 and based on the Technical Opinion 665,700, in addition to institutional authorization from Teresina Municipal Foundation.

\section{RESULTS}

Of a total of 261 health agents selected for the research, 243 agreed to participate.

The study group consisted of $70 \%$ female health agents. Mean age was 40.1 years (SD = 7.3). The vast majority of agents had at least a high school education (96.7\%); $43.6 \%$ had higher education.

Prevalence of sunscreen use in this risk group for skin cancer was 34.2\% (95\% CI: 28.2 to 40.2), if we consider the proper use of sunscreen every day. Considering the use of sunscreen on most days of the week, prevalence rose to $55.2 \%$ of health agents. Sixty-eight health agents (28\%) reported not using sunscreen (95\% CI: 22.3 to 33.7) (Table 1). Prevalence of use of sunscreen at the beach/ swimming pool was $69.5 \% ; 11.9 \%$ did not attend beach/ swimming pool.

The mean working time of these health agents was 10.3 years (SD 5.3), and $54.7 \%$ of them had 11 or more years of work in this position. In relation to sun exposure at work, $50.6 \%$ were exposed for up to six hours a day and $49.4 \%$ were exposed for seven hours or more a day. Mean daily exposure was 6.4 hours (SD 1.8). Sun exposure of $82.3 \%$ of health agents occurred in the interval between 9 am and 3 $\mathrm{pm}$, and most of them $(85.6 \%)$ were exposed while working.

For multivariate analysis, we considered all the factors that had a $\mathrm{p}<0.05$ to obtain the variables that justified the use of sunscreen by health agents. 
Use of sunscreen by female health agents was $18 \%$ higher than the use by male health agents $(p=0.001)$ (Table 2$)$. These data are consistent with those found in the literature.

Use of sunscreen had a statistically significant association with the age of health agents: its prevalence in the 41-63 years age group was $11 \%$ higher than in the other groups $(p=0.017)$ (Table 2$)$.

Regarding sociodemographic profile, education, skin color and skin type, when adjusted to each other, they showed no statistical association with the use of sunscreen in this risk group (Table 3).

Occupational characteristics, such as work time and work schedule, showed no statistical association with the use of sunscreen when adjusted for sociodemographic variables. On the other hand, the use of the sunscreen was more frequent among those who gave affirmative answers to questions relating to the knowledge about the skin, such as "do you use sunscreen when the skin is burnt?" And "do you know the sun's negative effects on the skin?". In relation to these two variables, adjusted for sociodemographic and occupational variables, the use by individuals who answered "yes" were $15 \%$ and $26 \%$ higher, respectively, than the use by those who gave negative answers $(\mathrm{p}=0.001)$ (Table 3 ).

Regarding the use of sunscreen out of work, it was observed an increase of $10 \%$ and $11 \%$ for "eventual use" and "use" during the weekends, respectively (Table 3 ).

Health agents who reported a history of skin cancer showed prevalence of sunscreens use $27 \%$ higher than that of who denied this history (Table 3).

\section{DISCUSSION}

Studies on the prevalence of sunscreens use in risk groups and its associated factors are scarce in the literature. All studies consider for analysis the daily use of sunscreen. Lucena et al, in 2014, studying the use of sunscreen by beach workers, found a prevalence of $80.1 \%$. Lima et al, in 2010 , found a prevalence of $53.83 \%$ of sunscreen use on health workers of Minas Gerais. In a population-based study in the South region of Brazil, the prevalence was $60.8 \%$ on the beach, $13.7 \%$ at work and $30.2 \%$ in outdoor activities. ${ }^{11-13}$ The last recorded data of the National Program to Fight Cancer, organized by the Brazilian Society of Dermatology, revealed prevalence of sunscreen use in Teresina of $19.76 \%, 19.95 \%, 32.27 \%$ and $23.31 \%$ in 2009, 2010, 2011 and 2013 respectively. ${ }^{5}$ A study conducted in 2012 analyzed data from 2009 and 2010 of the campaign against cancer held in Teresina and found a prevalence of $21.6 \%$ of sunscreen use in assisted individuals, $26.7 \%$ in patients diagnosed with skin cancer and $35.8 \%$ in patients with a family history of skin cancer. ${ }^{6}$ Another

TABLE 1: Prevalence of sunscreen use in the risk group for skin cancer participating in the study. Teresina, 2014

\begin{tabular}{llll} 
Sunscreen use & $\mathbf{n}$ & $\mathbf{0}$ & $\mathbf{9 5 \%} \mathbf{C I}$ \\
\hline Did not use & 68 & 28 & $22.3-33.7$ \\
Used less than half the days & 41 & 16.9 & $12.1-21.6$ \\
Used in half or most days & 51 & 21 & $15.8-26.1$ \\
Used everyday & 83 & 34.2 & $28.2-40.2$ \\
Total & $\mathbf{2 4 3}$ & $\mathbf{1 0 0}$ & -
\end{tabular}

Source: direct search study on college students habits in relation to sun exposure, also held in Teresina, identified higher use of sunscreen during voluntary sun exposure than in daily exposure (82.4\% versus $45.2 \%) .{ }^{14}$ In another study, conducted with physical education professionals of water activities directly exposed to the sun in Rio de Janeiro, the observed prevalence of sunscreen use was $17.9 \% .{ }^{15}$ Considering that the Brazilian Consensus on Photoprotection recommends the use of sunscreen by all people exposed to the sun, especially risk groups, it is clear that the observed prevalence was low, as well as in literature, although it is slightly higher than that found in the general population of the city studied. ${ }^{16}$

It is observed that, in general, this prevalence increases when there is intentional exposure to solar radiation. However, in a Spanish study with beachgoers (where there is an important intentional exposure), $30 \%$ of subjects reported that they did not consider the voluntary occasional exposure as a risk factor for skin cancer and that the application of sunscreen with a high protection factor would be enough to prevent sun damage, showing that perceived

TABLE 2: Sociodemographic, skin type and occupational profile of risk group for skin cancer participating in the study, according to sunscreen use. Teresina, 2014

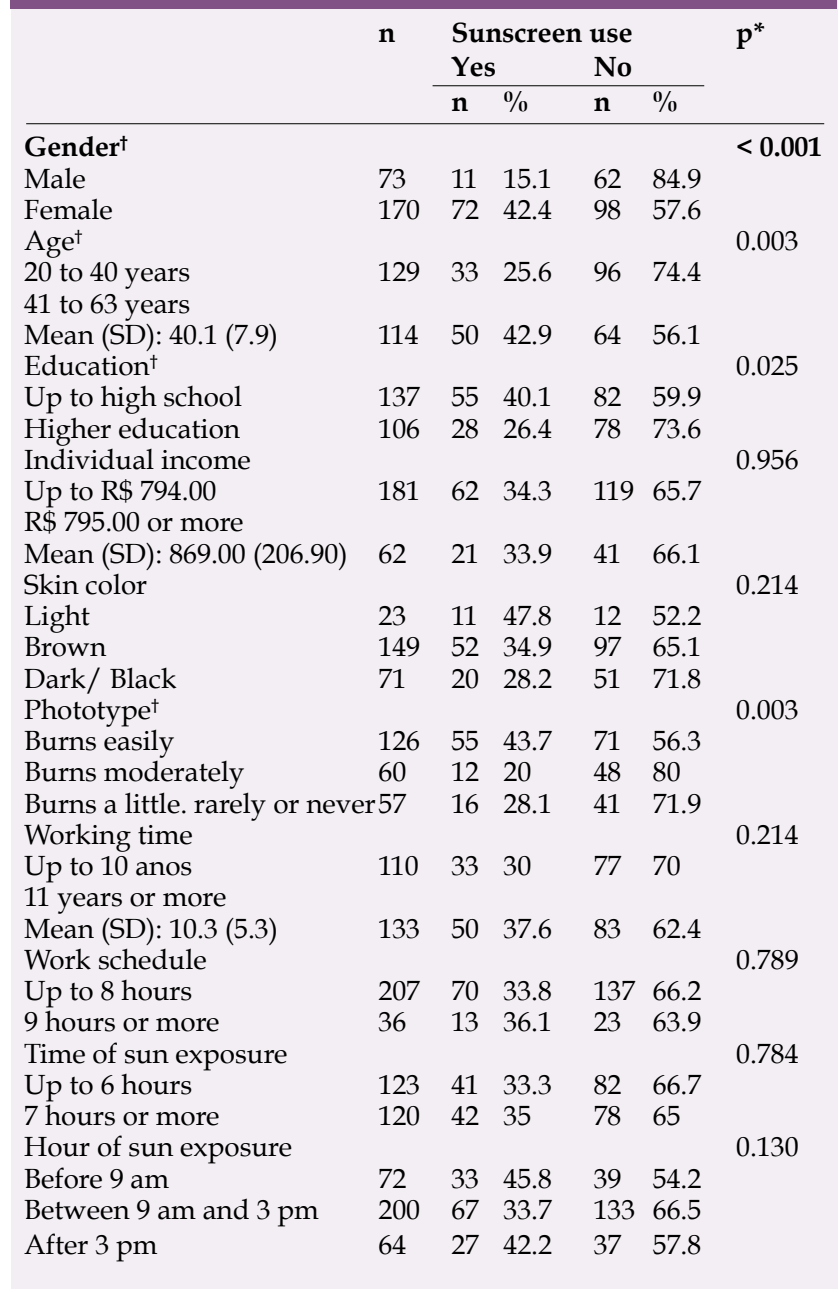

* Pearson's chi-square test $\left(\chi^{2}\right)$;

$\dagger$ Variable selected for multivariate analysis $(\mathrm{p}<0.05)$

Source: direct search 
susceptibility to skin cancer among these individuals is limited. ${ }^{2}$

It can be noted that much of the work time is occupied by activities exposed to the sun. Most workers perform these activities during the so-called "critical hours" (from 9 am to 3 pm), characterizing them as a labor risk group, with limits of solar radiation often exceeded. ${ }^{8}$

There was no statistical association in this sample between the use of sunscreen and time or hours of sun exposure while working. Nor studies were found relating these data, although there are already studies showing that the effects of solar radiation extend for up to three hours after the exposure to ultraviolet rays. There is a phenomenon in which occurs lesions and breaks in DNA, causing carcinogenesis mutations, hours after sun exposure. This process is independent of sunlight and occurs through a bombardment of free radicals and other substances that may have the same destructive effect (Table 2). ${ }^{17}$ Thus, the mean daily exposure of 6.4 hours, including the critical time, for most of this group of workers, suggests a prolonged damage effect.

There are several studies in the literature showing a higher prevalence of sunscreen use by women., ${ }^{2,8,14,15,18-21}$ This has been attributed to women behavior, who are more susceptible and more likely to engage and adopt healthy behavior practices and to have health care habits, in addition to more care about the aesthetics. ${ }^{21,22}$ It was also attributed to women a greater knowledge and a better attitude towards photoprotection, demonstrated by an exposure pattern derived from a lower performance of outdoor activities and the adoption of preventive measures due to a higher concern with cancer and premature skin aging., ${ }^{2,14}$
According to data obtained by the campaign for the prevention of skin cancer of the Brazilian Society of Dermatology in 2013, $73.15 \%$ of men and $54.16 \%$ of women are exposed to the sun without any protection. ${ }^{5}$

Although in this study the mean age was 40.1 years, the increased sunscreen use by older agents was consistent with the literature, which showed that age is inversely associated with sun exposure and directly related to "awareness" and to the habit of avoiding sun at noon. ${ }^{2,18}$

Regarding the sociodemographic profile, education, skin color and skin type, when adjusted to each other, they showed no statistical association with the frequency of sunscreen use in this risk group (Table 3). This finding is contrary to those found in the literature, which show evidence of a higher prevalence of sunscreens use among individuals with higher education. ${ }^{18,23}$

The affirmative answer to the question "do you use protection when the skin is burnt?" was associated with more frequent sunscreen use probably because - as noted by some researchers - the use of sunscreen can give a false sense of safety to those who use it. The burning sensation should not be experienced by those who use sunscreen, since it is indicative of the effect of solar radiation on the skin. Studies show that the use of sunscreen is associated with more frequent and longer duration of sunbathing, because many believe that the application of sunscreen is sufficient to avoid the damage of solar radiation on the skin.,24

In other studies, it was also observed a higher frequency of

TABLE 3: Prevalence of sunscreen use in the risk group for skin cancer participating in the study. Teresina, 2014

\begin{tabular}{|c|c|c|c|c|c|c|}
\hline & $\mathbf{P R}_{\text {gross }}$ & $95 \% \mathrm{CI}$ & $\mathrm{p}$ & $\mathbf{P R}_{\text {adjusted }}$ & $95 \% \mathrm{CI}$ & $\mathbf{p}$ \\
\hline \multicolumn{7}{|l|}{ Sociodemographic variables $1^{1}$} \\
\hline Gender & & & $<0.001^{*}$ & & & $0.001^{*}$ \\
\hline Male & 1.0 & & & & & \\
\hline Female & 2.81 & $1.59-4.98$ & & 1.18 & $1.07-1.30$ & \\
\hline Age group & & & $0.002^{*}$ & & & $0.017^{*}$ \\
\hline 20 to 40 years & 1.0 & & & & & \\
\hline 41 to 63 years & 1.71 & $1.20-2.46$ & & 1.11 & $1.02-1.20$ & \\
\hline Education & & & $0.022 \dagger$ & & & $0.059 \dagger$ \\
\hline Up to high school & 1.0 & & & & & \\
\hline Higher education & 0.66 & $0.45-0.96$ & & 0.92 & $0.84-1.00$ & \\
\hline Phototype & & & $0.002 \dagger$ & & & $0.108+$ \\
\hline Burns easily & 1.0 & & & & & \\
\hline Burns moderately & 0.46 & $0.27-0.79$ & & 0.89 & $0.80-1.00$ & \\
\hline Burns a little. rarely or never & 0.64 & $0.41-0.99$ & & 0.93 & $0.84-1.04$ & \\
\hline Knowledge on the skin ${ }^{2}$ & & & & & & \\
\hline Sunscreen use when the skin is burned ${ }^{\dagger}$ & & & $0.001^{*}$ & & & $0.001^{*}$ \\
\hline Yes & 1.88 & $1.03-3.44$ & & 1.15 & $1.01-1.34$ & \\
\hline No & 0.98 & $0.53-1.83$ & & 0.98 & $0.85-1.13$ & \\
\hline The skin does not get burned & 1.0 & & & & & \\
\hline Frequency of sun exposure off work & & & $0.038+$ & & & $0.040 \dagger$ \\
\hline Eventually & 1.63 & $1.05-2.53$ & & 1.10 & $1.01-1.21$ & \\
\hline On weekends & 1.68 & $1.02-2.78$ & & 1.11 & $1.01-1.23$ & \\
\hline Everyday & 1.0 & & & & & \\
\hline Knowledge of the sun's negative effects & & & $0.027^{*}$ & & & $0.004^{*}$ \\
\hline Yes & 2.66 & $1.22-4.80$ & & 1.26 & $1.08-1.48$ & \\
\hline No & 1.0 & & & & & \\
\hline Occurrence of skin cancer & & & $0.002^{*}$ & & & $0.007^{*}$ \\
\hline Yes & 2.29 & $1.47-3.55$ & & 1.27 & $1.07-1.50$ & \\
\hline No & 1.0 & & & & & \\
\hline
\end{tabular}

PR: prevalence ratio; IC: confidence interval; 1 Adjusted for each other; 2 Adjusted for sociodemographic and occupational variables; * Wald's test for linear trend; $\uparrow$ Wald's test Source: direct search 
sunscreen use in periods off work. These results may be due to the fact that intentional sun exposure and knowledge about the risk of skin cancer are important in deciding on the use of photoprotection. ${ }^{23}$

There are several studies showing a high prevalence of knowledge about the negative impacts of solar radiation. However, this knowledge seems to increase the prevalence of photoprotection only on voluntary exposure to solar radiation. In the labor risk groups, where the use of sunscreens should be daily, knowledge seems to fail to produce this effect. This shows that although individuals in these groups are aware of the risk of developing skin cancer, they lack the adoption of daily photoprotective measures. ${ }^{2,14,25-27}$

The observation that the presence of skin cancer history led to increased prevalence of sunscreen use was also made by Lages $e t$ $a l$, in 2012. It was found sunscreen use $14.2 \%$ higher by individuals who had a family history of skin cancer. ${ }^{6}$

\section{CONCLUSION}

Based on collected data, it can be concluded that the prevalence of sunscreen use by the studied community health agents is low, because they constitute a vulnerable group to the occurrence of skin cancer. Labor groups exposed to frequent solar radiation should have a greater prevalence of photoprotection than the general population.

The factors associated with increased use were: female sex, older age, situations where the skin was burned, exposure off work, knowledge of the negative effects of the sun on the skin and skin cancer history.

These results confirm the need to adopt measures aimed at protecting the skin of these workers and health education strategies in order to raise awareness on the photoprotection, not only in risk groups, but also in the general population, in order to decrease the incidence of skin cancer. We suggest the conduction of more studies related to this important topic with the objective of strengthening its scientific basis. $\square$

17. Premi S, Wallisch S, Mano CM, Weiner AB, Bacchiocchi A, Wakamatsu K, et al. Chemiexcitation of melanin derivatives induces DNA photoproducts long after UV exposure. Science. 2015;347:842-7.

18. Duquia RP, Menezes AM, Almeida HL Jr, Reichert FF, Santos Ida S, Haack RL, et al. Prevalence of sun exposure and its associated factors in southern Brazil: a population-based study. An Bras Dermatol. 2013;88:554-61.

19. Castilho IG, Sousa MAA, Leite RMS. Fotoexposição e fatores de risco para câncer da pele: uma avaliação de hábitos e conhecimentos entre estudantes universitários An Bras Dermatol. 2013;88:554-61.

20. Molgo M, Castillo C, Valdes R, Romero W, Jeanneret V, Cevo T, et al. Conocimientos y habitos de exposicion solar de la poblacion chilena. Rev Med Chile. 2005;133:662-6.

21. Fabris MR, Durães ES, Martignago BC, Blanco LF, Fabris TR. Assessment of knowledge of skin cancer prevention and its relation with sun exposure and photo protection amongst gym academy members on the south of Santa Catarina, Brazil. An Bras Dermatol. 2012;87:36-43.

22. Rasmussen S, O'Connor RC. Factors influencing anticipated decisions about sunscreen use. J Health Psychol. 2005;10:585-95.

23. Szklo AS, Almeida LM, Figueiredo V, Lozana Jde A, Azevedo e Silva Mendonça $\mathrm{G}$, Moura Ld, et al. Behaviors related to sunlight exposure versus protection in a random population sample from 15 Brazilian State capitals and the Federal District, 2002-2003. Cad Saude Publica. 2007;23:823-34.

24. Autier P, Doré JF, Négrier S, Liénard D, Panizzon R, Lejeune FJ, et al. Sunscreen use and duration of sun exposure: a double-blind, randomized trial. J Natl Cancer Inst. 1999;91:1304-9.

25. Devos SA, Baeyens K, Van Hecke L. Sunscreen use and skin protection behavior on the Belgian beach. Int J Dermatol. 2003;42:352-6.

26. Simões TC, Souza NVDO, Shoji S, Peregrino AAF, Silva D. Medidas de prevenção contra câncer de pele em trabalhadores da construção civil: contribuição da enfermagem. Rev Gaúcha Enferm. 2011;32:100-6.

27. Bardini G, Lourenco D, Fissmer MC. Avaliação do conhecimento e hábitos de pacientes dermatológicos em relação ao câncer da pele. ACM Arq Catarin Med. 2012;41:56-63.

\footnotetext{
MAILING ADDRESS:

Fernanda Ayres de Morais e Silva Cardoso

Rua Anfrísio Lobão, 1.415, ap. 1.101 - Jockey

64048-230 - Teresina - PI

Brazil

Email:fernandaayres@gmail.com
}

How to cite this article: Cardoso FAMS, Mesquita GV, Campelo V, Martins MCC, Almeida CAPL, Rabelo RS, Rocha AEA, Santos JLO. Prevalence of photoprotection and its associated factors in risk group for skin cancer in Teresina, Piauí. An Bras Dermatol. 2017;92(2):206-10. 